\title{
THE SUCCESSFUL INCORPORATION OF BLENDED LEARNING INTO THE LANGUAGE CURRICULUM
}

\author{
Adam J. Simpson \\ Sabanci University, School of Languages, Istanbul, Turkey \\ adams@sabanciuniv.edu
}

\begin{abstract}
A phenomenon attracting increasing attention in language curricula is the infusion of technology into traditional, face-to-face (FTF) language instruction. Nevertheless, computer-assisted language learning (CALL) still lacks a body of qualitative research on the notion of blended learning (BL). Particularly, what is lacking is information regarding teachers' perceptions of blended learning, or the roles they are expected to play in such mixed environments; without an understanding of these issues, the creation of new and effective BL curricula is extremely difficult (Grgurovic,2010). That said, much research has been conducted comparing learning outcomes in traditional and blended foreign language classes, although the various socio-cultural (external) and psychological (internal) aspects governing the successful transition of both teachers and learners from FTF to online learning remain unexamined (White,2006). This literature review consequently focuses on the infusion of technology into the language curriculum, specifically in relation to BL, with three purposes in mind: to a) exemplify teacher perspectives on BL; b) their effective transition from FTF to technologicallyenhanced instruction; and c) examine those factors which are identified as the reasons for teachers having effectively implemented the technological components into a blended curriculum.
\end{abstract}

Keywords: Blended learning; hybrid courses; educational technology.

1. Introduction. As societies change in response to challenges in the social, political and economic arenas, so do their education systems (Kelly, 2009). Consequently, Information Communication Technologies (ICTs) are now commonplace in curricula. Indeed, technology should be viewed as offering valuable alternatives to teachers and educational institutions (Kerres \& De Witt, 2003).

However, when it comes to incorporating technology into language courses, even the most accepting and forward-thinking institutions may not make consistently sound curricular choices. Indeed, every language teacher could benefit from asking the following pertinent questions (Berk, 2010):

- How do I decide which technology to use in my classroom?

- What criteria, if any, do I use to make informed choices regarding technological tools?

- Are these criteria related to my learners' features, pedagogy, and learning outcomes?

With or without reference to such questions, we are witnessing the expanding prevalence of technology components within education:

"Over the last two decades, educational improvement efforts have placed increased emphasis on curriculum standards and on having the multiple parts of the education system reinforce each other as part of an aligned system. An outgrowth of this trend has been a renewed interest in linking technology and curriculum."

(Smith \& O'Day, 1990, in Means, 2008, p. 14)

This embracing of technology within language teaching has fostered numerous teaching and learning practices. As far as tertiary education, in which I teach, is concerned, great strides have been made in investigating the possibilities of BL. The main reasons for this are the need to: be flexible in delivering education; address the challenges of geographic distance, and; deliver higher education on a global scale (Bach, Haynes and Smith, 2006). Consequently, BL, the model that integrates online with traditional FTF learning, has become a favored strategy of many English preparatory university programs in attempting to meet the requirements of language learners, institutions, and local and national educational authorities.

Despite the wealth of research illustrating the multifarious difficulties of implementing technology-mediated innovation, systematic analysis of the roles, perceptions and practices of language teachers in BL models is lacking. As Shelley et al. (2006, p. 2) note: 
"The emergence of a host of new ways of organizing language learning over the past two decades... has not been met with a similar development of enquiry into what is actually required to carry out teaching roles in such contexts."

Additionally, the various socio-cultural (external) and psychological (internal) aspects which influence the transition from FTF to BL, remain under-examined (White, 2006). Furthermore, there remains a lack of information on the perceptions of teachers and the roles they play in $\mathrm{BL}$ environments; without an understanding of these, the creation of effective BL courses is difficult (Grgurovic, 2010). Nevertheless, "the approach of blending Computer-assisted Language Learning (CALL) applications with FTF teaching and learning is as old as CALL itself" (Neumeier, 2005, p. 163 ), and there are sufficient overlaps in the body research for many conclusions to be drawn in terms of language learning.

In this literature review, I will specifically examine the incorporation of technology into the curriculum. In doing so, I will address White's, Grgurovic's and Neumeier's concerns, firstly by discussing what has been examined in research studies on blended language learning (BLL), and secondly looking at what is still to be addressed. I will also consider how teachers respond to the notion BL, their perceptions, roles and practices, as well as externalities that influence how they respond to technological course content and delivery.

I begin with an examination of the origins of BL in higher education contexts, its definitions, and its implications in terms of course design. Certain studies examining the impact of BLL courses as well as teachers' views about BL are then revisited. My goal is to: a) examine those characteristics influencing teachers' transitions from FTF to blended/online instruction; and b) suggest directions for future research regarding how language teachers may come to terms with BL courses.

\subsection{The Origins, Definitions, and Design of Blended Learning}

1.1.1 Origins. BL is not new; somewhat surprisingly, the term has been around for approximately 25 years. First emerging in the business world (Sharma, 2010), it was quickly accepted into education due to: i) the accessibility of computers in and outside the classroom, ii) the growth in pedagogical opportunities for teaching and learning (Hong \& Samimy, 2010), and iii) the disillusionment in online learning lacking traditional classroom elements (McDonald, 2008).

Jonassen et al. (2003) contend that there is an ever growing need for learners at tertiary level to not only learn English, but also widen their technological skills to enable them to be competitive in the global marketplace. Nevertheless, the challenge is "to make sure that the focus on technology does not distract from the focus on knowledge, knowledge creation, its evolution and application" (Bach, Haynes \& Smith, 2006, p. 16). Laurillard reiterates: "a university is defined by the quality of its academic conversations, not by the technologies that service them" (Laurillard, 2002, in Motteram, 2006, p. 19).

Despite the contention that there is nothing new about BL, institutions that use blended approaches do so on the premise that both FTF interaction and online methods have inherent, albeit distinct, advantages, and therefore are beneficial for teachers and learners (Neumeier, 2005). For instance, BL enables teachers to foster a flexible and active learning environment that may positively influence learners' experiences and outcomes, and to spend more time with learners, both individually and in small groups (Davis and Fill, 2007; Tayebinik and Puteh, 2012; Oh and Park, 2009). Indeed, blended instruction offers "improved pedagogy, easy access to knowledge, more interaction among learners, personal presence, cost effectiveness, and ease of revision of learning content" (Tayebinik \& Puteh, 2012, p. 28).

1.1.2 Definitions. One issue I faced was finding a definitive description; what I found was a varied range of meanings. Tayebinik and Puteh (2012) compiled a comprehensive review of definitions, ranging from the general to the specific. They suggest that Driscoll (2002) provides the broadest definition of all authors, since she defines BL simply as a combination of instructional methods or pedagogical approaches. A more commonplace general definition sees BL described as a mixture of online learning or web-based training with FTF communication and more traditional methods (Gülbahar \& Madran, 2009; Rovai \& Jordan, 2004; Thorne, 2003; and Y1ldırım, 2007). Neumeier (2005) stresses the importance of a 'single teaching and learning environment' when defining BL as a hybrid of FTF and computer assisted learning. 
Sharma and Barrett (2007), however, define BL in general terms as a course which combines FTF classroom components with 'appropriate use' of technology:

"The term technology covers a wide range of recent technologies, such as the Internet, CDROMs and interactive whiteboards. It also includes the use of computers as a means of communication, with applications such as chat and e-mail, and a number of environments which enable teachers to enrich their courses, such as VLEs (virtual learning environments), blogs and wikis." (2007, p. 7)

For Sharma and Barrett, BL is, therefore, applicable to a great many teaching and learning environments.

Elsewhere, Sharma (2010) notes different definitions and stances. The term blend has been used to refer to; the combination of technologies (email, internet, phone, etc.); methodologies (TBLT, for instance); the mix of teaching modes (FTF and CALL), and; real and virtual worlds (Second Life). Similarly, Lim, Morris and Kupritz (2007) focus on three definitions they regard as being representative: i) a learning method with multifarious delivery modes that optimizes learning outcomes and reduces program delivery costs; ii) any mix of technology-based learning with instructor-led training methods, and; iii) the mix of innovative technologies with traditional and interactive-rich forms of classroom education (Lim, Morris and Kupritz, 2007, p. 28). Singh and Reed (2001, in Lim et al., 2007) reiterate to a certain extent, proposing six combinations of BL:

i) offline/online learning; ii) self-paced, live, and collaborative learning; iii) structured/unstructured learning; iv) customized content and 'off-the-shelf' content, $v$ ) work and learning, and; vi) blending synchronous physical formats, synchronous online formats, and selfpaced, asynchronous formats (Lim, Morris and Kupritz, 2007, p. 28).

Nonetheless, Neumeier (2005) postulates that the distinction between the two is no longer unambiguous, as contemporary classrooms commonly feature advanced mobile technology, i.e. FTF instruction no longer implies an absence of technology. As Crook (1994, in Neumeier, 2005) suggests: "It becomes obvious that this distinction becomes increasingly blurred as we interact with, around, at, in relation to and through computers" (Neumeier, 205, p. 165). Indeed, Claypole (2010, in Sharma, 2010) sees little new in BL; it is, he states, merely a logical response to the development of earlier pedagogical tendencies involving diverse methods of teaching. Westbrook (2008) reaffirms this, stating that in the future the term may become redundant and eventually disappear because of the sheer number of definitions attached to it.

1.1.3 Design. When considering BL design, the most important aim is to find "the most effective and efficient combination of the two modes of learning for the individual learning subjects, contexts and objectives" (Neumeier, 2005, p. 165). Indeed, as Sharma (2010, p. 457) sees it, BL seeks to develop a reasoned balance between technological activities and FTF human interaction; it, therefore, remains an important concept in language teaching, as "its overall focus is concerned with the attempt to identify the optimum mix of course delivery in order to provide the most effective language learning experience."

Another important consideration when creating a balanced BL environment is the various uses of online media. Harasim (2000, in McDonald, 2008) identifies two modes: adjunct and mixed. In the former, technology use merely enhances traditional FTF instruction, whereas the latter sees a significant part of the curriculum purposefully developed online. Given that the content, skills and strategies which were formally the sole domain of the traditional classroom are now being designed and studied in virtual settings, it is evident why the role of design is greatly discussed in BL.

As mentioned, the combination of FTF and online learning means that the BL model is being increasingly utilized in tertiary education institutions in response to contemporary social, economic and pedagogical challenges. According to Bach, Haynes and Smith (2006), online learning (and BL) is proliferating alongside contemporary changes in higher education, themselves reactions to globalization and the expansion of higher education across the globe. This increase in the demand suggests "a reduction of input costs and resources in relation to the number of output graduates" (Bach, Haynes \& Smith, 2006, p. 10). To cope with this demand, institutions are employing various policies, of which a reduction in direct classroom teaching input and the greater use of technology 
linking classroom activity with self-directed study are two (ibid). The role of technology is key, as it enables institutions to ensure that programs can maintain high quality even when FTF instruction is decreased.

Furthermore, as Fullan (1997) notes, BL "offers opportunities to construct actively networked learning communities that grow consistently in response to the demands of a global need" (Fullan, 1997, p. 5). Consequently, this model, which aims to effectively utilize and combine FTF instruction with Computer-Mediated Communication (CMC) and web-mediated tools, is being widely implemented in language programs in tertiary institutions to both meet the needs facing contemporary higher education and to enhance language learning/teaching processes (Grgurovic, 2010). For an institution to reap the benefits that BL offers, it must address the challenges related to course design: a "threat of an out-of-balance, discordant blend ...[may] frustrate both learner and teacher" (Osguthorpe \& Graham, 2003, p. 229). The authors state that to find the appropriate mix between FTF and technological activities, designers, curriculum leaders and teachers need to answer several pedagogical and logistical questions, namely:

i) how often learners will complete assignments technologically versus how often they meet teachers FTF; ii) what will be accomplished during these FTF meetings versus during the online experiences; iii) how often learners and their teacher will interact in the technological environment, and what the purpose of such interaction will be, and; iv) how communities will be built during both types of contact (ibid).

Institutions must, additionally, offer pedagogical richness, access to knowledge that goes beyond textbooks, social interaction, and opportunities for autonomous learning (ibid).

These different design- and pedagogical-related issues have led to the formation of various approaches to the planning and evaluation of blended frameworks. In this review, I will primarily focus on two of these models.

Neumeier (2005) establishes a set of parameters for BL design. Neumeier discusses two stages: i) focus on mode (selection of lead mode) and ii) model of integration. In focus on mode, either FTF or technological delivery is given prominence so as to guide the structure and the learning process of the course. The choice is made after careful evaluation of the learning objectives, the learners and the infrastructural resources available. In the model of integration, learning content and objectives are distributed, the tasks pertaining to both modes are organized and sequenced, and the optional or obligatory nature of each of these tasks is determined.

Picciano (2009) proposes a somewhat different model: "The Multimodal Model" takes into consideration the fact that learners represent different personality types, different generations, and different learning styles. Given the need for teachers and curriculum designers to use multifarious approaches to meet the needs of this wide spectrum of learners, Picciano presents a framework of five basic pedagogical objectives and activities: i) the use of multiple technologies in the delivery of content; ii) the incorporation of questioning (the Socratic Method) to investigate what learners know and to improve their knowledge; iii) the incorporation of reflection on the learning process; iv) the implementation of collaborative learning, and; v) the synthesis, evaluation and assessment of learning. Picciano posits that the main advantage of multiple modalities is that "they allow learners to experience learning in ways in which they are most comfortable while also challenging them to experience and learn in other ways as well" (Picciano, 2009, p. 16).

2. Review of the literature. In response to the issues affecting BL, research has largely examined the experiences of the relevant parties in course implementation (noted in Larsen, 2012, p. 5). In the area of language teaching specifically, Grgurovic (2011) notes that empirical studies investigating the use of BL models with language learners have been conducted as either comparison or non-comparison studies. Whereas comparison studies question the effectiveness of BL by comparing blended instruction with traditional instruction (specifically, this would refer to FTF without CALL instruction), non-comparison studies research BL program design and implementation, as well as learner and teacher attitudes regarding BL (Grgurovic, 2011, p. 102). I will discuss these comparison and non-comparison studies, in particular, those that examine or provide information about teachers' roles, practices, and views towards BL programs, as these are issues of importance to my context. 
2.1 My context. I work in a tertiary level preparatory program at a university in Istanbul. Technology is embedded in the curriculum. For example, students use their computers regularly in the classroom, many writing assignments are word-processed and communication is conducted through e-mail and course websites. Additionally, a virtual learning environment (VLE) is consistently used as a part of our courses inside and outside the classroom. Time and resources are allocated to the development of this resource in terms of creating teaching materials for classroom use that utilize the Internet and the available technology.

As a member of the department's technology team, I am directly involved in the development of the technological skills of instructors and students. In-house teacher development includes sessions on the effective use of technology in teaching and learning English that aim to enrich instructors' skills in the effective use of technology and provide a forum for the sharing of ideas. Guidance and training are provided to students in the effective use of technology in learning English. Nevertheless, because of time factors, the main focus of my involvement is on maintenance of the VLE and administrative duties (typical administrative duties include checking grade entry has been done correctly by teachers, and uploading and dispersing assessment information). This is to the detriment of activities, such as teacher training and dealing with teachers' resistance to technology, which are given lower priority.

2.2 Blended Learning and its influence on teaching roles. Research on the roles and attitudes of teachers in blended learning varies greatly in terms of results and conclusions reached. These differences appear to depend on the contextual, theoretical and methodological considerations that guide their design. In this part of the literature review I will primarily focus on the five comparison (Murday, Ushida \& Chenoweth, 2006,2008) and non-comparison studies (Bañados, 2006; Bijeikien, Rašinskien \& Zutkien, 2011; Comas-Quinn, 2011 and Hong and Samimy, 2010) which explore both the advantages and challenges of BL programs and which are of particular relevance to my context. Within these studies, I will particularly examine those factors which are identified as the reasons for teachers having effectively implemented the technological components into that blended curriculum.

2.3 Assessment and course satisfaction. Murday et al.'s (2006, 2008) study looked at the assessment results of a blended language course which took place at Carnegie Mellon University. The data were gathered via course evaluations, interviews, and focus groups. The effectiveness of the BL format was compared with traditional courses by examining measurable outcomes, i.e. learning outcomes and the level of satisfaction reported by instructors and learners. While the study indicated that blended courses were successful, with an increasing level of satisfaction over time, no statistically significant difference between the grades learners obtained in the two courses was evident; learning outcomes were similar in both contexts.

In terms of satisfaction, the results were somewhat mixed. For teachers, recurring themes included: the need for training; control over course materials, and; a lack of connectivity with the learners. Learners noted many positives: the ability to work at their own pace; the ability to listen to target language sound clips repeatedly; the ability to access translations when needed, and; the enjoyment of the more casual nature of the interactions during chat sessions. Nevertheless, certain difficulties were reported in making the transition from FTF to online learning: the technological component of the blended program caused some difficulties when switching from the traditional coursebook to electronic text; learners needed self-discipline and effective self-directed strategies, and; various technological issues needed to be dealt with.

2.4 The need for training. As mentioned, one significant aspect of teaching a BL course was training, since the technology that made such classes possible caused difficulties in teachers' lives whenever there were technical problems. Nevertheless, as Murday et al. (2006, 2008) note, such difficulties brought about a strong communal effort among teachers in coming to terms with managing the online component of the course, which was somewhat different from managing traditional FTF environments. Therefore, despite these issues, the blended program was evaluated as a positive experience; the problems faced during implementation were outweighed by the benefits in terms of learning and satisfaction. 
2.5 Impact on linguistic competence. Bañados (2006) initiated a somewhat similar study, exploring the impact of the implementation of a pilot ESL blended program at a university in Chile. The research addressed the effect of BL on learners' linguistic competence and their levels of satisfaction. The data indicated that learners' oral competence improved significantly, with notable progress in all the other skills, too. The language learning experiences they had on the course were also favorably evaluated.

Regarding teachers, Bañados postulates that the 'dual role' of teacher and online tutorinitiated positive qualitative changes in teachers' roles, as they became guides and collaborators who supported the learners' learning process. However, it also meant a numerical increase in the hours they dedicated to learners: "Teachers spend only 1.5 hours a week in FTF classes, but they spend a larger number of hours managing learners' work in the online environment" (Bañados, 2006, p. 541). Through managing this language learning environment, they had to construct favorable conditions for language acquisition, which in turn helped learners "develop learning strategies and become autonomous and confident learners, able to manage a language learning system which relies strongly on their ability to work independently" (ibid). Despite this clear change in participant roles, Bañados, like Murday et al. (2006, 2008), maintains that these findings support BL model implementation, as language learning was significantly improved.

2.6 Impacts on the teacher. Undoubtedly the biggest finding to come out of the literature review was the ways in which BL impacts teachers. Comas-Quinn (2011), rather than examining language learning performance, evaluated the effects of introducing a distance language learning BL course at the Open University from the teachers' point of view. Their qualitative and quantitative data comprised of interviews, class observations, a survey and an institutional report Findings indicated that, for teachers, online tools were unsuccessfully integrated; they considered tools such as blogs and tutor group forums either unnecessary or not useful. Indeed, some noted that the BL experience had merely increased their workload.

Comas-Quinn states: "The success of any innovation in education, such as the introduction of online teaching and online technologies (what is commonly referred to as e-learning), is in great part due to how well teachers deal with the new ideas and implement them with their learners" (ComasQuinn, 2011, p. 219). Consequently, teachers' acceptance and use of ICT greatly influences learners' approval of online learning, as well as their perceptions of how useful online tools are. Similarly, learners' expectations strongly influence teachers' willingness to adapt, alongside traditional ideas shared by colleagues and learners about "what language learning is and what their respective roles in the process are" (Ibid, p. 228). Likewise, they are influenced by their own individual beliefs and values, as well as other internal and external motivators.

Contemporary professional development programs, Comas-Quinn suggests, do not always consider these various influences, making adaptation less likely to occur. Lamentably, the 'transmission of knowledge' approach to training neither acknowledges nor supports the change in teacher identity that happens when moving from the traditional classroom- based teaching to BL teaching. As the research indicates, this adaptation goes beyond the acquisition of technological skills; such a move necessitates a pedagogical understanding of the new environment and recognition of this new role and identity (Comas-Quinn, 2011, p. 218).

Similarly, Hong and Samimy (2010) examined the role of teachers in successful BL implementation, although they did so from a different angle; in their study data were gathered from learners instead of teachers. They particularly explored the relationship between language learners' reactions to BL and teachers' use of CALL modes. A questionnaire was given to 255 learners; questions asked about learners' attitudes towards their use and their teachers' use of CALL, as well as other issues related to demographics, the time devoted to web use, and previous BL experiences. Findings validated the notion that learners whose teachers incorporated CALL tools to a 'lesser extent' exhibited less favorable attitudes toward the online component in BL than those learners taught by teachers who actively used technology. Consequently, and reaffirming ComasQuinn's supposition, teachers' attitudes toward and uses of technology undoubtedly influence learners' attitudes towards and their acceptance of the use of technology. Intriguingly, Hong and Samimy (2010) further noted that factors like teacher experience with a blended environment and 
higher literacy computer skills were not as significant in shaping learners' positive attitudes towards a BL environment as was teachers' dynamic use of CALL.

Finally, Bijeikien et al.'s (2011) study examined language teachers' experiences with CALL, as well as their practices and attitudes towards BL courses. Their research was conducted in the Centre of Foreign Languages at Vytautas Magnus University, with 24 teachers of English, via qualitative techniques, such as informal interviews and a questionnaire The teaching and learning process was enhanced through technological resources and activities designed and made available through a virtual Moodle environment (Bijeikien et al., 2011, p. 123). Findings revealed both positive and negative responses. Teachers positively valued the convenience of access, the learner-centered approach and the communicative practice, since learners were able to work independently and consistently. Nevertheless, the main drawback was the lack of FTF contact; certain learners needed more assistance and guidance with tasks. Moreover, teachers regarded learners' low motivation to participate in the virtual chats and forums as exacerbating this issue.

Their findings indicate that, while teachers valued the learners' autonomous learning fostered by the BL environment, those aspects of BL which focused on teacher input were considered possibly problematic. The authors offer two explanations for this: on the one hand, although teachers espouse the notions of independence and autonomy in BL, they may still prefer the traditional FTF interaction in teacher-learner relationships. Conversely, teachers might remain unsure about the usefulness of such contact with their learners, simply because they sense they are lacking competence and experience in e-communication (Bijeikien et al., 2011, p. 125).

\section{The application of theory to practice}

While the cases mentioned in this part of my review are in some ways a continuation of the literature review, I felt it pertinent to begin applying them to my context, as there were so many ideas that were immediately applicable. These case studies show varying results: whereas certain researchers contend that learner exposure to the BL model enhances language learning, others observe no significant improvement in comparison with more conventional instruction techniques. As far as satisfaction levels are concerned, different opinions are also witnessed. Nevertheless, taking into account the variance in methods and results, perhaps the most significant aspect noted in the studies, and the one I must consider in my context, is the need for both teachers and learners to adapt their approach. Despite BL necessitating the combination of FTF and technological instruction, many more difficulties are therefore encountered with the technological component of such courses; both parties must adapt to changes in roles and to the need for new knowledge and skills. Bañados (2006) exemplifies, stating that learners must start taking responsibility for their own learning process, while teachers must assume the roles of online tutors, producers of media resources, material designers, and managers of the learning environment. Consequently, "learners, like teachers, may favor one of the delivery modes to the detriment of the other" (Sharma, 2010, p. 457).

The more important change, I believe, is for teachers: becoming online tutors requires a quantitative increase in the number of hours dedicated to learners, in addition to acquiring new skills. Most importantly, though, teachers must undergo a change in identity, because there are new roles and pedagogical perspectives to be considered (Comas-Quinn, 2011). As Bijeikien et al. (2011, p. 123) observe, "it is not only the quest of what ICT to blend in and how much of it would allow for the best results, but also [a] wish to keep pace with the technology that burden language teachers nowadays." Clearly we can see that BL challenges not only the conventional roles of learners, but also those of teachers and course materials. Furthermore, notions and expectations as to what, when and how teaching and learning occur are modified.

\subsection{Further difficulties in 'Blending'}

3.1.1 Specialist training. As mentioned, most of my time as a member of my department's technology team is devoted to administration and system maintenance. Given the following examples, this seems to be an issue I should endeavor to address.

Compton (2009), concurring with Hampel and Stickler (2005), states that the online context of BLL has engendered a need for new teaching approaches and teaching skills, unlike those employed in FTF language teaching. Teachers not only need different skills from those required in FTF language classrooms, but also different from online teachers of other subjects. Compton 
postulates that any notion of a good FTF language teacher being able to easily adapt to this new medium is a myth. Indeed, Easton (2003, in Compton, 2009) contends that online instructors need to undergo paradigm shifts in terms of; perceptions of instructional time and space; virtual management techniques, and; ways of engaging learners through virtual communications (Compton, 2009, p. 75).

Bennett and Marsh (2002, in Compton, 2009) suggest two important aspects of knowledge which go beyond this technical level. Teachers engaging with technology must: "i) identify the significant differences and similarities between FTF and online learning and teaching contexts, and; ii) identify strategies and techniques to facilitate online learning and help learners exploit the advantages in relation to both independent and collaborative learning" (Compton, 2009, p. 76). Teachers involved in blended programs are, generally, FTF instructors as well as BL tutors. While such teachers generally cope effectively with the FTF model, they might not necessarily know how to implement the technological component of their course: "online language teachers cannot be expected to become effective based on training meant for FTF classrooms when these two environments involve different skills and responsibilities" (Ibid, p. 96).

Hampel and Stickler (2008, p. 315-316) reiterate, noting that online classroom management differs from a FTF classroom:

"Online tutors have to not only help learners to develop their technical skills in using the virtual environment but also constantly be aware of benefits and challenges of online learning. They have to be familiar with the technology and know about the implications that the medium has in the context of teaching a language. They have to rely on their expertise as language teachers and knowing how to use virtual environments in the context of useful approaches to language learning... They also need to develop the skill of creating online communities or social entities for language learning."

The authors therefore suggest that many problems BL teachers face echo those encountered in FTF classes. This notwithstanding, other issues necessitate specific training for BL language teachers. Mortera-Gutierrez (2006) reiterates, contending that successful BL implementation does not equate to providing FTF teachers with computer communication technology and simply expecting them to develop satisfactory skills, rather, "it is training them with pedagogical and didactical tools, and teaching them how to handle blended learning courses" (Mortera-Gutierrez, 2006, p. 335). In terms of implications for my context, I need to consider how help can be given in terms of recognizing and coping with the pedagogical demands of BL.

3.1.2 First- and second-order barriers to technology use. In addition to this need for specific training, the development of new skills, and a sound online pedagogy, other aspects also influence teachers' effective adoption of technology-mediated practices. In 1999, Ertmer (in Ertmer et al., 2012) recognized two barriers that impinge on teachers' utilization of classroom technology. First-order barriers are those external to the teacher, including resources, training, and support. Second-order barriers, which are internal, include personal confidence, beliefs about teaching and learning, and the perceived value of technology to the teaching/learning process. Their conclusion is intriguing:

"Although first-order barriers had been documented as posing significant obstacles to achieving technology integration, underlying second-order barriers were thought to pose the greater challenge" (Ertmer et al., 2012, p. 423).

Several studies examine these first- and second-order barriers. Demetriadis et al. (2003) investigated teachers' attitudes towards the incorporation of ICT into the classroom. Their research was conducted as part of a training project in secondary schools in Greece. Their findings indicate a willingness to investigate and implement ICT as and when there is compatibility with established methodologies and curriculum, but only when their own views about what is meaningful and effective for their learners is respected. Hughes (2005), reporting the pedagogical experiences of four language arts teachers, similarly states that the adoption and use of innovative technology-supported pedagogy can only be effective when it matches a teacher's interpretation of the value of technology in supporting classroom instruction and learning. This is important for me in my context, as I witness cases where teachers see technology as being incompatible with their methods, when it in fact isn't so. 
Intriguingly, Hughes' data actually reveals the compatibility of tech tools with traditional teacher-centered methods. Hughes, therefore, states that technology in education has the potential to innovate, yet also to maintain the status quo. Teachers might, therefore, make use of technology "in ways that are least distant from their practice" to uphold - rather than innovate - current pedagogical practice (Hughes (2005, p. 280). Indeed, Dat (2002, in Tomlinson, 2005) observes that, particularly when trying out new methodologies, teachers tend to teach according to their established standards and beliefs. If said beliefs give rise to the conclusion that learners won't benefit from new technology, teachers frequently maintain the status quo and shy away from change. I now see the need to acknowledge such influences when attempting to work with teachers to develop their use of technology.

Nevertheless, embracing the status quo does not necessarily negate the possibility of change or adaptation. Quite the opposite, such acceptance of current norms may result from the social roles assigned to teachers. Demetriadis et al. (2003) concur with Billet (2001), asserting that "the specific socially imposed requirements of a particular [job] influence the way that the abstracted knowledge of the occupation is manifested in practice" (Demetriadis et al., 2003, p. 31). In other words, teachers are subject to a situational nature of expertise, in which certain factors become an impediment to the adoption of innovative learning methods. The fact that teachers feel compelled to help learners pass examinations, for instance, may discourage a more transformative use of technology. Again, these are factors I must acknowledge more explicitly.

Such constraints are typical of what many teachers and learners experience, and are evident in my teaching context. Sugar, Crawley and Fine (2004) also considered assessment - official testing, specifically - in their study of teachers' beliefs about technology adoption. Their study analyzed the beliefs of six high school teachers regarding the extent to which they felt able to adopt technology. They surmised that participants' use of technology was limited by the type of knowledge and skills required in official examinations. Technology use was therefore restricted to activities that seemingly facilitated testing training, i.e. those which helped learners pass exams. Furthermore, personal factors are not the only things influencing teachers' adoption of new technology; we also see normative factors, such as the support or approval it can receive from other stakeholders (other stakeholders might include parents, administrators and principals, among others), as well as contextual elements like training, time, budget, and standardized testing (Sugar et al., 2004, p. 205).

Likewise, McGrail (2005) and Finley and Hartman (2004) indicate that many teachers fail to see the connection between increased technology use and the realization of educational objectives. Consequently, no advantage is perceived over other methods. For example, teachers in McGrail's study "resisted pressure from the administration to use technology in their classrooms when they felt it was not as effective as other alternatives available to them" (McGrail, 2005, p. 18). Their resistance resulted from not perceiving tangible benefits, despite being aware of the potential advantages of BL. As with all the points raised here, this issue of effectively showing the connection between technology and objectives is something for me to consider further.

3.2 The keys to teacher satisfaction. Despite differences in terms of methodological approaches, these studies agree on one fact: teachers will consistently be unwilling to implement technological tools if they feel there is "a lack of a clearly articulated vision for appropriate technology use" (Finley \& Hartman, 2004). Moreover, enabling access to online resources will not necessarily result in effective use either by teachers or by all learners, because there's no guarantee they will experience the benefits of these resources. Indeed, both parties may even feel marginalized because their traditional, trusted methods and information sources are no longer being used (Bach, Haynes \& Smith, 2006).

Demetriadis et al. (2003) stress the importance of keeping in mind certain 'conditions' so as to understand teachers' behavior and their enthusiasm or reluctance to embrace ICT. For instance, teachers generally wish to feel that: i) ICT use enhances the quality of teaching and their professional image (effectiveness); ii) ICT use will not disrupt the intended course of action or obstruct the curricular goals they desire to achieve (avoidance of disturbances); and iii) they are confident in their use of the tools (feeling of control). A breakdown in any one of these conditions will lead to tension; a process of negotiation between the teacher, the institution and the ICT culture must be initiated. 
Another important consideration for me is teachers' prior learning experiences with technology, as this will also mediate the interpretation of the value of ICT (Hughes, 2005). Comas-Quinn (2011) contends that such past experiences and accumulated knowledge play a crucial role in how they use technology in their teaching. As mentioned elsewhere, this highlights a need in my context for training to show how technology can enhance teaching.

4. Conclusion. Borg $(2003,2003$, p. 95) postulates that the social, psychological and environmental realities of a school or classroom "may hinder language teachers' ability to adopt practices which reflect their beliefs". These realities include parents, principals' requirements, the school, society, curriculum mandates, classroom and school layout, school policies, colleagues, standardized testing, and the availability of resources. Evidently, teachers' perceptions of technology are affected by numerous contextual and personal aspects, which in turn influence the kind of learning opportunities they offer their learners. Regardless of whether they are involved in BL or in other programs where technology is used in more conventional ways, these external and internal factors often shape teachers' experiences with technology. While the aforementioned research on BL often suggests important practical and pedagogical implications for language learning and teaching, it nonetheless fails to consider the various professional and personal factors affecting the transition that teachers experience when moving from fully FTF environments to blended environments. Future research may wish to focus on not only on measurable outcomes, such as language performance and levels of satisfaction, but also on the internal and external realities that are part of teachers' lives, since they also have a bearing on how teachers interpret and implement BL.

While technology assumes an ever-increasing role in our lives, so it gains increasing prominence in the pedagogical frameworks and curricula of educational institutions: "whether teachers accept technology or not, academic institutions [continue] mandating integration of technology into academic programs" (White, 2006, p. 18). Consequently, Hamper and Stickler's (2008) assertion, that conducting research into teachers' attitudes and teaching styles, their use of technological media, and their awareness of the different interaction patterns of online and FTF communication would benefit the development of BL instruction, holds true.

As Hong and Samimy maintain (2010), the question of whether language teachers and learners benefit from BL's intended efficacy has not been fully substantiated. The literature has yet to confirm real improvements, not merely in language learning, but also in terms of language pedagogy. As White (2006) notes, there is still a tendency among teachers to allow technological tools to direct or shape their instructional choices, rather than technology serving pedagogical aims.

Whereas learning technology has progressed, the same cannot be said of technological pedagogies: "As innovations in technology and practice have clearly outstripped theory development, the use of technology in learning environments has tended to be technology-rather than theory-led" (White, 2006, p. 250). Therefore, research based on theoretical and methodological perspectives is requisite in understanding how teachers might better come to terms with new pedagogical practices.

5. Recommendations for further research. White notes several questions that BL research has not yet addressed, questions that may be resolved by examining the knowledge of second language acquisition theories, as well as certain other disciplines. Potential questions that might be addressed by language researchers in the future include: how learning is socially constructed in virtual learning environments; what technological pedagogies materialize in BL environments, and; which socio-cultural, psychological or personal factors hinder language teaching.

Of these, the most pertinent for my own context would be to further research the latter, as comparisons of the learning outcomes of traditional and BLL courses, the various socio-cultural and psychological aspects which mediate the transition from FTF to online learning, seem to remain as yet unexamined (White, 2006). In this literature review, I have frequently recognized the need for training, coupled with the fostering of teacher satisfaction, comfort and understanding of how BL can complement their current methods and practices. I envisage research focusing on the perceptions of teachers and the roles they play in BL environments from the perspective of what is needed in terms of a training program, with regard to how the aforementioned barriers might best be overcome. 


\section{References:}

Arbaugh, J. B. (2004). Learning to learn online: a study of perceptual changes between multiple online course experiences. Internet and Higher Education, 7(3), 169-182. http://dx.doi.org/10.1016/j.iheduc.2004.06.001

Bach, S., Haynes, P., \& Smith, J. L. (2006). Online learning and teaching in higher education. Buckingham, UK: Open University Press.

Banados, E. (2006). A blended-learning pedagogical model for teaching and learning EFL successfully through an online interactive multimedia environment. CALICO Journal, 23(3), 533-550.

Berk, R. A. (2010). How do you leverage the latest technologies, including Web 2.0 tools, in your classroom? International Journal of Technology in Teaching and Learning, 6 (1), 1-13.

Bijeikienè, V., Rašinskienè, S., \& Zutkienè, L. (2011). Teachers' attitudes towards the use of blended learning in general English classroom. Studies about Languages, 18, 122-127.

Blake, R. J. (2008). Brave new digital classroom: Technology and foreign language learning. Washington, D.C.: Georgetown University Press.

Borg, S. (2003). Teacher cognition in language teaching: A review of research in what language teachers think, know, believe, and do. Language Teaching, 36, 81-109. http://dx.doi.org/10.1017/s0261444803001903

Comas-Quinn, A. (2011). Learning to teach online or learning to become an online teacher: An exploration of teachers' experiences in a blended learning course. ReCALL, 23(3), 218-232. http://dx.doi.org/10.1017/s0958344011000152.

Compton, L. (2009). Preparing language teachers to teach language online: A look at skills, roles, and responsibilities. Computer Assisted Language Learning, 22(1),73-99. http://dx.doi.org/10.1080/09588220802613831.

Darling-Hammond, L., \& Bransford, J. (2005). Preparing teachers for a changing world: What teachers should learn and be able to do. San Fransisco, CA: Jossey-Bass Education Series.

Demetriadis, S., Barbas, A., Molohides, A., Palaigeorgiou, G., Psillos, D., Vlahavas, I., \& A. Pombortsis, A. (2003). Cultures in negotiation: Teachers' acceptance/resistance attitudes considering the infusion of technology into schools. Computers and Education, 41, 19-37. http://dx.doi.org/10.1016/s0360-1315(03)00012-5

Desai, M. S. H., Jeff, R., \& Thomas C. (2008). E-learning: Paradigm shift in education. Education, 129(2), $327-334$.

Ertmer, P., Ottenbreit-Leftwich, A., Sadık, O., Sendurur, E., \& Şendurur, P. (2012). Teacher beliefs and technology integration practices: A critical relationship. Computers \& Education, 59, 423-435. http://dx.doi.org/10.1016/j.compedu.2012.02.001

Eseryel, D. (2002). A Framework for Evaluation and Selection of E-Learning Solutions. In M. Driscoll \& T. Reeves (Eds.), Proceedings of World Conference on E-Learning in Corporate, Government, Healthcare, and Higher Education 2002 (pp. 275-282). Chesapeake, VA: AACE.

Finley, L., \& Hartman, D. (2004). Institutional change and resistance: A teacher preparatory faculty and technology integration. Journal of Technology and Teacher Education, 12(3), 319-327.

Fullan, M. (Ed.). (1997). The challenge of school change: A collection of articles. New York: Hawker Brownlow.

Garrison, D.R., \& Kanuka, H. (2004). Blended learning: Uncovering its transformative potential in higher education. The Internet and Higher Education.7(2), 95-105. http://dx.doi.org/10.1016/j.iheduc.2004.02.001

Gomez, K. L., Sherin M. G., Griesdorn, J., \& Finn, L. (2008). Creating social relationships: The role of technology in preservice teacher preparation, Journal of Teacher Education, 59(2), 117-131. http://dx.doi.org/10.1177/0022487107314001.

Gribbins, M. L., Hadidi, R., Urbaczewski, A., \& Vician, C. (2007). Technology enhanced learning in blended learning environments: A report on standard practices. Communications of the Association for Information Systems, 2007(20), 741-759.

Grgurovie, M. (2010). Technology-enhanced blended language learning in an ESL class: A description of a model and an application of the diffusion of Innovations theory. Unpublished doctoral dissertation, Iowa State University.

Grguroviè, M. (2011). Blended learning in an ESL Class: A case study. CALICO Journal, 29 (1), 100-117. http://dx.doi.org/10.11139/cj.29.1.100-117

Hampel, R., \& Stickler, U. (2005). New skills for new classrooms: Training tutors to teach languages online. Computer Assisted Language Learning, 18(4), 311-326. http://dx.doi.org/10.1080/09588220500335455

Hong, K., \& Samimy, K., (2010). The influence of L2 teachers' use of CALL modes on language learners' reactions to blended learning. CALICO Journal, 27(2), 328-348. http://dx.doi.org/10.11139/cj.27.2.328-348

Hughes, J. (2005). The role of teacher knowledge and learning experience in forming technology- integrated pedagogy. Journal of Technology and Teacher Education, 13(2), 277-289.

Jonassen, D. H., Howland, J., Moore, J., \& Marra, R. M. (2003). Learning to solve problems with technology: A constructivist perspective (2nd ed.). Upper Saddle River, NJ: Merrill Prentice Hall.

Kelly, A. V. (2009). The curriculum: Theory and practice (6th ed.). London: SAGE.

Larsen, L. (2012). Teacher and student perspectives on a blended learning intensive English program writing course. Graduate Theses and Dissertations. Paper 12375

Laurillard, D. (2002). Rethinking University Teaching. A conversational framework for the effective use of learning technologies (2nd ed.). London: Routledge. http://dx.doi.org/10.4324/9781315012940

Lamie, J. (2005). Evaluating change in English language teaching. New York: Palgrave Macmillan. http://dx.doi.org/10.1057/9780230598638.

Lim, D., Morris, M., \& Kupritz, V. (2007). Online vs. blended learning: Differences in instructional outcomes and learner satisfaction. Retrieved September, 2012 from: http://sloanconsortium.org/ jaln/v11n2/online-vs-blendedlearning-differences-instructional-outcomes-and-learner-satisfaction 
Lo Bianco, J. (2010). Language policy and planning. In N.H. Hornberger \& S.L. McKay (Eds.), Sociolinguistics and language education (pp. 143-174). Bristol, UK: Multilingual Matters.

MacDonald, J. (2008). Blended learning and online tutoring: A good practice guide. Aldershot, UK: Gower.

McGrail, E. (2005). Teachers, technology and change: English teachers' perspectives. Journal of Technology and Teacher Education, 13(1), 5-14.

Means, B.(2008). Technology's role in curriculum and instruction. In F. M. Connelly, M. F. He, \& J. Phillion (Eds.), The SAGE Handbook of Curriculum and Instruction (pp. 123-145). Thousand Oaks, CA: SAGE. http://dx.doi.org/10.4135/9781412976572.n7

Mortera-Gutierrez, F. (2006). Faculty best practices using blended learning in e-learning and face-to- face instruction. International Journal on E-learning, 5(3), 313-337.

Motteram, G. (2006). Blended education and the transformation of teachers: a long-term case study in postgraduate UK education. British Journal of Educational Technology, 37(1), 17-30. http://dx.doi.org/10.1111/j.1467-8535.2005.00511.x

Murday, K., Ushida, E., \& Chenoweth, N. A. (2006). Learner learning in hybrid French and Spanish courses: An overview of language online. CALICO, 24(1), 115-145.

Murday, K., Ushida, E., \& Chenoweth, N. A. (2008). Learners' and teachers' perspectives on language online. Computer Assisted Language Learning, 21(2), 125-142. http://dx.doi.org/10.1080/09588220801943718

Neumeier, P. (2005). A closer look at blended learning: Parameters for designing a blended learning environment for language teaching and learning. ReCALL 17(2), 163-178. http://dx.doi.org/10.1017/s0958344005000224

Osguthorpe, R.T., \& Graham, C.R. (2003). Blended learning environment: Definitions and directions. The Quarterly Review of Distance Education, 4(3), 227-233.

Picciano, A. (2009). Blending with purpose: The multimodal model. Journal of Asynchronous Learning Networks, 13(1), 7-18.

Sharma, P. (2010). Blended learning. ELT Journal, 64(4), 456-458. http://dx.doi.org/10.1093/elt/ccq043

Sharma, P., \& Barret, B. (2007). Blended learning: Using technology in a beyond the language classroom. Thailand: Macmillan Publishers Limited.

Shelly, M., White, C., Baumann, U., \& Murphy, L. (2006). 'It's a unique role!' Perspectives on tutor attributes and expertise in distance language teaching. International Review of Research in Open and Distance Learning, 3(2), 1-14.

Sugar, W., Crawley, F., \& Fine, B. (2004). Examining teachers' decisions to adopt new technology. Educational Technology and Society, 7(4), 201-213.

Ricento, T., \& Hornberger. N. (1996). Unpeeling the onion: Language planning and policy and the ELT professional. TESOL Quarterly, 30(3), 401-427. http://dx.doi.org/10.2307/3587691

Tayebinik,M., \& Puteh, M. (2012). Blended learning or e-learning? IMACST, 3(1), 103-110.

Tomlinson, B. (2005). English as a foreign language: Matching procedures to the contexts of learning. In E. Hinkel (Ed.), Handbook of research in second language teaching and learning (pp.137-154). Mahwah, NJ: Lawence Erlbaum Associates.

Westbrook, K. (2008). The beginning of the end for blended learning? IATEFL CALL Review. Summer 2008: 12-15.

White, C. (2006). Distance learning of foreign languages. Language Teaching, 39, $247-264$. http://dx.doi.org/10.1017/s0261444806003727 